\title{
El didactismo landivariano: tradición clásica, identidad cultural e ideología jesuítica \\ en la Rusticatio Mexicana
}

The Didacticism in Landívar: Classical Tradition, Cultural Identity, and Jesuitic Ideology in the Rusticatio Mexicana

\author{
Marcela Alejandra SuÁREZ \\ Universidad de Buenos Aires / CONICET \\ malesu@arnet.com.ar / marcela.suarez@conicet.gov.ar
}

\begin{abstract}
RESUMEN: En el marco de la literatura neolatina, la poesía didáctica ha tenido un amplio desarrollo sobre la base del modelo virgiliano. Pero la "popularidad del género" se debe al interés que despertó entre los jesuitas de los siglos XVII y XVIII. Tal el caso del P. Landívar, autor de la Rusticatio Mexicana. El análisis de las convenciones genéricas pone de manifiesto que el didactismo landivariano se nutre de la tradición clásica y revela un carácter identitario y claramente ideológico.
\end{abstract}

ABSTRACT: Within the framework of the Neo-Latin literature, didactic poetry has had a broad development on the basis of the virgilian model. But the "popularity of the genre" is due to the interest aroused among the Jesuits of the seventeenth and eighteenth centuries. Such is the case of Landívar, Rusticatio Mexicana's author. The analysis of the generic conventions shows that the didacticism of Landívar nourishes itself from the Classical tradition and reveals a clear ideological character and identity.

PALABRAS ClAVE: Rafael Landívar, tradición clásica, identidad cultural, ideología jesuítica. KEY WORDS: Rafael Landívar, Classical tradition, cultural identity, Jesuitic ideology.

RECIBIDO: 20 de agosto de 2012 - ACEPTADO: 24 de enero de 2013.

Al referirse a las formas y géneros literarios neolatinos, Ijsewijn (1977, p. 264) afirma: "every literary form, genre, theme and even minor peculiarity which can be found in ancient Latin and Greek literature has seeped into Neo-Latin in one way or another". Siguiendo el principio de la imitatio et aemulatio ueterum, los escritores neolatinos vuelven sus ojos hacia los clásicos no sólo para imitarlos, sino para superar a sus modelos genéricos.

Según la valoración clásica y humanista, la poesía didáctica ocupa, junto con la épica, el sitial más alto en la jerarquía de los géneros poéticos ${ }^{1}$

${ }^{1}$ Al referirse a la poesía didáctica latina, afirma Pozzi 2010, p. 105, "la poesía didáctica es una especie textual de elusiva definición, compleja sistematización e incierta justificación”. 
y en el marco de la literatura neolatina se encuentra abundantemente representada. ${ }^{2}$ Los grandes poemas didácticos de este período han sido concebidos sobre los modelos de la antigüedad clásica. ${ }^{3}$ Según Kromer (1979, p. 9), la influencia de dichos modelos determina, en cierta medida, los rasgos formales del género que reflejan el contrato entre el autor y la audiencia. ${ }^{4}$

En el siglo XVI, el modelo virgiliano, sobre todo, ${ }^{5}$ marca el florecimiento de la poesía didáctica en Francia e Italia. Así salen a la luz poemas sobre la agricultura y el arte de los jardines. ${ }^{6}$ Pero la "popularidad del género" se debe, en realidad, al interés que despertó entre los jesuitas de los siglos XVII y XVIII. Dicha popularidad puede explicarse en función de los principios pedagógicos y a partir de la ideología de la Compañía de Jesús. ¿Qué otro género podía resultar más apropiado que el didáctico, siendo los jesuitas los maestros modernos por excelencia? ${ }^{7}$

${ }^{2}$ Cf. Ijsewijn-Sacré 1998, p. 24; van Tieghen 1966, p. 302.

${ }^{3}$ Con respecto a los modelos literarios de este género, la tradición griega puede clasificarse en arcaica y helenística. Dentro de la primera se ubica Hesíodo, con Los trabajos y los días, y dentro de la segunda, Arato, con su obra Phaenomena, y Nicandro de Colofón, autor de Georgica (poema didáctico perdido), Theriaca (tratado acerca de los remedios contra las mordeduras venenosas) y Melissurgica (tratado sobre las abejas). Entre los antecedentes latinos, cabe mencionar a Catón y a Varrón, destacados por sus tratados De Agricultura y Res Rusticae.

${ }^{4}$ Entre las convenciones genéricas, se destacan las siguientes: $a$ ) Autoridad y superioridad del poeta: el poeta que aspira a cumplir el papel de maestro debe establecer primero su autoridad, la cual se revela frecuentemente a partir de la invocación a la divinidad vinculada con el tema a tratar. En cuanto a la superioridad, el poeta la enfatiza empleando el imperativo y amonestando a sus lectores a prestar atención. $b$ ) Establecimiento del tema y presentación de la materia a partir de amplios proemios y de la articulación de las partes expositivas y argumentativas. Cumplen, en este punto, un papel fundamental las descripciones, las argumentaciones retóricas y las digresiones. c) Destinatario: de todas las convenciones que definen al género, la figura del destinatario es la que la crítica temprana toma como base para reconocer el significado de la poesía didáctica.

${ }^{5}$ En realidad, el gran árbol de la poesía didáctica está representado por tres ramas: Lucrecio, Virgilio y Manilio.

${ }^{6}$ Giovanni Pontano, Girolamo Vida, Rapin y Vanière son algunos de los poetas didácticos más reconocidos.

${ }^{7}$ La Compañía de Jesús nace en un ambiente educativo, el de los compañeros fundadores que se habían formado en la Universidad parisina, viviendo en sus distintos colegios. No se establecieron como una sociedad de maestros, sino de sacerdotes reformados y suficientemente instruidos, aunque es indudable la prioridad educativa a lo largo de su trayectoria desde el s. XVI en adelante. Además del género didáctico, se valieron del drama escolar y del emblema para desplegar sus ideales pedagógicos. Cf. Burrieza Sánchez 2010, p. 180. 
La posición clave que ocupa la poesía en el corazón de los Studia Humanitatis, ${ }^{8}$ que regula la Ratio Studiorum, le confiere a la escritura del verso latino un propósito educacional. En este sentido, la poesía didáctica viene a cubrir las nociones de poesía y pedagogía al fusionar el antiguo binomio clásico del delectare y el docere. ${ }^{9}$

Los integrantes de la Compañía de Jesús componen y consumen una gran variedad de poesía y prosa latinas, para luego apropiarse del género didáctico y contribuir a enriquecer la tradición o la microtradición local en virtud de la improntaideológica de sus producciones científicas y literarias. ${ }^{10}$

En este artículo nos proponemos abordar la Rusticatio Mexicana, poema didáctico del P. Rafael Landívar, uno de los jesuitas más destacados del s. XVIII en Nueva España, ${ }^{11}$ para definir su didactismo sobre la base del análisis de ciertos pasajes que reflejan el contrato entre el autor y su audiencia.

Si bien toda la literatura es didáctica, pues transmite valores ideológicos e impone una agenda de manera implícita o explícita, ${ }^{12}$ hay determinados textos que eligen como vehículo la ficcionalización literaria de un proceso de enseñanza. ${ }^{13}$

Volk (2002) señala cuatro marcas esenciales de la poesía didáctica: intención didáctica explícita, constelación maestro-alumno, autoconciencia poética y simultaneidad poética. ${ }^{14}$

${ }^{8}$ El sistema pedagógico jesuítico denominado Ratio Studiorum (1599) se dividía en Estudios inferiores, en los que se impartía Gramática latina (ínfima, media y superior), Retórica y Humanidades, y en Facultades superiores, cuyas materias eran Sagrada Escritura, Lengua hebrea, Teología Escolástica, Casos de conciencia, Filosofía, Filosofía Moral y Matemáticas. En las clases de gramática, los alumnos aprendían latín y, en menor medida, griego, y recibían conocimientos básicos de cultura grecolatina. En las clases de Humanidades y de Gramática se proponía el estudio de una serie de autores, en su mayoría latinos, necesarios para garantizar la buena formación de los estudiantes. En estas áreas la lectura, la memorización y la imitación de la poesía latina ocupaban un lugar relevante. Se aconsejaban expresamente Virgilio, Ovidio, Horacio, Séneca, Marcial, Tibulo, Propercio, Terencio, Estacio, Claudiano, Galo, Ausonio e incluso Catulo y Plauto, siempre expurgados en ediciones ad usum scholarum Societatis Iesu. Cf. Gil 1992.

${ }^{9}$ Cf. Haskell-Hardie 1999, p. 10.

${ }^{10}$ Cf. Haskell 2003, p. 6.

${ }^{11}$ Otros autores representativos de este siglo son Abad, Alegre y Clavigero.

12 Cf. Habinek 1998, p. 3.

${ }^{13}$ Cf. Sharrock, en Gibson 1997, pp. 99-115.

${ }^{14}$ La enseñanza se desarrolla de manera simultánea con la lectura del poema, se despliega en un presente de enunciación continuo ("ahora te explicaré", "entenderás más 
Landívar, a lo largo de su extenso poema, apela a algunos de estos elementos paradigmáticos del género, sin dejar de exhibir su variación creativa. Valiéndose del principio de la imitatio et aemulatio ueterum, enuncia en I.7-17 una suerte de tabla de contenidos en la que están representados los quince libros del poema: ${ }^{15}$

Me iuuat omnino, terrae natalis amore, usque uirescentes patrios inuisere campos, mexiceosque lacus, et amoenos Chloridis hortos undique collectis sociis percurrere cymba: Tum iuga Xorulli uisam, Vulcania regna; et uitreos celso latices de colle ruentes; coccineumque dein, Tyriumque, Indumque uenenum: oppida mox fibri telis, ferroque fodinas aggrediar; luteisque astringam sacchara formis: hinc fusum regione pecus, fontesque sequutus et uolucres, et lustra canam, ludosque docebo. ${ }^{16}$

Según se advierte en este breve proemio, el poeta manifiesta su intención didáctica al poner en funcionamiento un proceso de enseñanza explícito expresado mediante el uso del lexema verbal docebo.

Desde la antigua formulación serviana, la presencia de dos figuras o personae, el que enseña y el que aprende,${ }^{17}$ resulta fundamental. Esta

adelante") y simbolizada por metáforas e imágenes que hacen referencia a la creación poética como un viaje o un camino.

${ }^{15}$ El poeta muestra diligencia para escribir acerca de temas tan variados, en muchos casos vinculados con rubros económicos, y disciplina para organizar el material y disponerlo desde el punto de vista retórico, valiéndose de dos tipos de escritura: el discurso de la ciencia y el discurso poético. El paradigma de cada libro - propositio et inuocatio - refleja una fluctuación, una tensión entre lo protocolar y lo emocional, la misma que se da entre el Monitum y la Oda a Guatemala. Cf. Laird 2006, pp. 56-57.

${ }^{16}$ Landívar R. M. I.7-17: "Me llena de placer, por amor a la tierra natal, visitar los campos paternos siempre en flor, y recorrer en piragua con amigos provenientes de todas partes los lagos mexicanos, los amenos jardines de Flora. Entonces contemplaré la cima del Jorullo, reino de Vulcano, y los manantiales cristalinos que fluyen desde las alturas; luego el zumo de la grana, el tirio y el indiano; enseguida me encaminaré con flechas a las ciudades del castor y con la barreta a las minas; recogeré en moldes de barro la miel de caña; de allí iré tras el ganado esparcido por la región y tras las fuentes, celebraré las aves y las fieras y enseñaré los juegos".

${ }^{17} \mathrm{El}$ comentario de Servio en la introducción de las Geórgicas (G. I.26-28) es el primer testimonio antiguo conservado que define los componentes mínimos del género: Hi libri didascalici sunt, unde necesse est, ut ad aliquem scribantur; nam praeceptum 
constelación maestro-alumno, expuesta por medio de vocativos, órdenes y marcas que indican un receptor en situación de aprendizaje, no está ausente en la Rusticatio, tal como se desprende del siguiente pasaje: ${ }^{18}$

Tum uigil incultae glebae perpende uigorem; quod uersata ferat semen, quod dura recuset, ${ }^{19}$ quoque tibi lucro facienda impendia possit reddere; quae uideas nigris compacta medullis aequora, crede mihi, turgescunt ubere gleba, ${ }^{20}$ nec meliora satis praestat natura ferendis. ${ }^{21}$

et doctoris et discipuli personam requirit: unde ad Maecenatem scribit sicut Hesiodus ad Persen, Lucretius ad Memmium ("Estos libros son didascálicos, de donde la necesidad de que sean escritos para alguien; en efecto, el precepto requiere del maestro y del discípulo: de ahí que le escribe a Mecenas como Hesíodo le escribe a Perses y Lucrecio a Memmio"). Acerca de otras fuentes, cf. Diomedes Ars 3.483 K; Tractatus Coislinianus.

${ }^{18}$ Landívar R. M. V.19-24: "Después examina atento la calidad de la tierra virgen, qué semilla recibirá una vez aflojada y cuál rechazará la de duro terrón y también con qué beneficio podrá resarcirte la que debe ser cultivada. Créeme, las vegas compactas de negras entrañas que puedas ver están reventando de fecundidad y la naturaleza no proporciona otras mejores para dar frutos".

${ }^{19}$ El v. 20 resulta una clara alusión a G. I.53: et quid quaeque ferat regio et quid quaeque recuset. Este hexámetro virgiliano es analizado por Farrell (1991, pp. 94-95) como ejemplo que ilustra el fenómeno de la contaminatio. Este método, que se define como un proceso de combinación de pasajes por alusión múltiple, en el nivel más elemental, se convierte en un modo de condensar una fuente. Teniendo como modelo a Lucrecio, Virgilio combina elementos de versos adyacentes: el v. 53 de Geórgicas es una condensación de Lucrecio: et quid quaeque queant per foedera naturai, / quid porro nequeant, sancitum quandoquidem exstat (I.586-587). Sin embargo, en el pasaje landivariano, la reminiscencia lucreciana se pierde, lo cual determina la lectura y la reescritura que el jesuita lleva a cabo de su modelo.

${ }^{20}$ Los cultivos dependen de la tierra, que les prodiga alimento. La tierra negra es la más conveniente por su fertilidad. De ahí que el antigüeño escriba turgescunt ubere gleba activando su memoria poética y dejándose llevar por el estro del mantuano que en Aen. III.164 exalta el doble mérito de Italia: terra antiqua, potens armis atque ubere glaebae. Es de notar que Landívar refracta la imagen de la fertilidad - ubere gle$b a-$, que ocupa los dos últimos pies del segundo hemistiquio, del mismo modo que en Virgilio. Por medio de la alusión contextual, el guatemalteco, en relación con su tierra, silencia la dimensión épica y amerita la geórgica.

${ }^{21}$ En virtud de que los llanos de morenas entrañas son los más fecundos, la naturaleza no puede proporcionar otros mejores para la siembra. El final landivariano nec meliora satis praestat natura ferendis (R. M. V.24) nos remite a G. II.177-178: Nunc locus aruorum ingeniis, quae robora cuique, quis color et quae rebus natura ferendis. Este 
La segunda persona del singular del imperativo y subjuntivo exhortativo (perpende / uideas) permite identificar claramente la relación entre un ego docens y un tu discens, es decir, un enunciador que asume un papel didáctico y configura a su enunciatario como alumno o aprendiz.

En algunos pasajes aparece un nos ("nosotros") inclusivo acompañado del modo indicativo (Postquam Neptuni uitreos inuisimus agros), ${ }^{22}$ que atenúa la tensión de los interlocutores y sugiere un enunciador que acompaña el proceso de aprendizaje. Esta característica favorece la idea de que aprendizaje y lectura son actividades que se desarrollan de manera simultánea.

Uno de los aspectos fundamentales de la poesía didáctica es el carácter binario del emisor, pues es magister y poeta. El principio de autoridad se funda entonces sobre la combinación de la esfera del saber y la maestría poética. Por tal razón, en el carmen landivariano se dan cita tanto figuras divinas de autoridad vinculadas con el tema a tratar, ${ }^{23}$ como las que están relacionadas con el canto y la poesía. ${ }^{24}$

fragmento es otro ejemplo de combinación de pasajes por alusión múltiple (G. I, Aen. III, G. II), herramienta de gran potencial que Landívar sabe explotar en su poema.

${ }^{22}$ Landívar R. M. IV.1: "Después que visitamos los campos cristalinos de Neptuno".

${ }^{23}$ Landívar R. M. I.28-31: Tu, qui concentus plectro moderaris eburno, / et sacras cantare doces modulamina Musas, / tu mihi uera quidem, sed certe rara canenti / dexter ades, gratumque melos largire uocatus ("Tú, que conciertas música con el ebúrneo plectro y les enseñas a las sagradas Musas a modular armonías, propicio y convocado para prodigar una grata melodía, asísteme a mí, que canto asuntos, en verdad, reales, pero poco frecuentes"). Cabe señalar que en estos versos el poeta establece el patrón de acuerdo con el cual compondrá los restantes cantos: invocación personal a las Musas y a distintas divinidades. En la invocación a Apolo que sigue el estilo clásico, Landívar entabla un diálogo intertextual con Propercio (siue lyrae carmen digitis percussit eburnis, 2.1.9) y Ovidio (en tibi deuoto nomine dexter ades, Fast. 1.6).

${ }^{24}$ Landívar R. M. IV.5-11: Tu, quae puniceo, Tritonia Virgo, colore / intextos auro regum perfundis amictus, let Lydam laetaris acu uicisse puellam; / dic mihi, quae dederit regio tibi prouida fucos, / atque orbem cocco, Tyrioque impleuerit ostro; / quis legat haec campis, quae mittant semina terrae / et quo nascantur regalia germina cultu ("Tú, Virgen Tritonia, que tiñes de color púrpura los mantos reales entretejidos de oro y que te alegras de haber vencido a la doncella Lidia con la aguja, dime qué próvida región te ha dado los jugos y ha llenado el orbe con grana y múrice tirio; quién los recoge en los campos, qué semillas arrojan a la tierra y con qué cultivo nacen los gérmenes reales"). Nótese que Landívar se refiere a Minerva como Tritonia Virgo. En este sentido, dice Higgins (2000, p. 169): "With the formulation of this rhetorical request to Tritonia, he is able to integrate the account of the dye's elaboration into the order of universal knowledge and value derived from classical antiquity". El empleo del adje- 
Asimismo, el mencionado carácter binario del enunciador didáctico determina una suerte de autoconciencia poética que lo lleva a reflexionar sobre su oficio, tal como se lee en la recusatio inicial del L. I.1-6:
Obtegat arcanis alius sua sensa figuris, abstrusas quarum nemo penetrare latebras ausit, et ingrato mentem torquere labore; tum sensum brutis aptet, gratasque loquelas; impleat et campos armis, et funere terras, omniaque armato debellet milite regna. ${ }^{25}$

Como representante del movimiento neoclásico, Landívar reniega de la estética barroca porque produce textos oscuros, tenebrosos e incapaces de producir placer. Al respecto, afirma Nemes (1971, p. 303): "he refuses to join ranks with the imitators of Aesopo or La Fontaine or with those Hispanic poets who exalted the armed victories of a nation long in a period of military decadence". Sin embargo, Laird (2006, p. 68), al referirse a los vv. 1-6, sostiene: "these opening verses themselves display a capacity for allegorical or figurative expression which will be shown in many of the books to follow". Su autoconciencia poética se refuerza en el v. 7, donde deja en claro su posición por medio del empleo del lexema iuuat, que evoca la apología de la poesía del De Rerum Natura. ${ }^{26}$

Por medio de diversas formulaciones, el magister-poeta devela su ideología, aquella que lo atraviesa en tanto sujeto histórico. En este sentido, conviene recordar que el ideario pedagógico de la congregación resalta seis virtudes cardinales (disciplina, diligencia, destreza, demostración, dificultad y distinción ${ }^{27}$ ) que, insufladas en el ámbito áulico

tivo Tritonius/a/um es una marca léxica y semántica, es decir, un modo de reconocer la alusión virgiliana, tal como se desprende del siguiente ejemplo: armipotens, praeses belli, Tritonia uirgo (Aen. XI.483). Ovidio, en cambio, emplea: talibus adfata est breuiter Tritonia dictis (Met. II.783); hactenus aurigenae comitem Tritonia fratrem (Met. V.250); praebuerat dictis Tritonia talibus aures (Met. VI.1). Asimismo, cabe destacar la alusión al mito de Aracne (cf. Verg. G. IV.246; Ov. Met. VI.5-145) que le permite introducir el tema de la industria de la grana y la púrpura.

25 "Oculte otro sus pensamientos bajo símbolos misteriosos, para que nadie ose penetrar sus abstrusas tinieblas ni torturar la mente con desagradable esfuerzo; atribuya entonces razón y gratas palabras a los animales; colme los campos de armas y las tierras de muerte y arrase todos los reinos bajo escuadrones guerreros."

${ }^{26}$ Cf. Lucr. I.926-950; IV.1-50.

${ }^{27}$ Entendida esta última en términos de diferencia, claridad y precisión. 
desde la infancia, se reflejan más tarde en la escritura madura de los poetas.

Dichas virtudes se manifiestan a lo largo del poema landivariano, pero algunas están anticipadas en el Monitum ${ }^{28} \mathrm{o}$ advertencia al lector:

Rusticationis Mexicanae huic carminis praefixi titulum, tum quod fere omnia in eo congesta ad agros Mexicanos spectent, tum etiam quod de Mexici nomine totam Nouam Hispaniam uulgo in Europa appellari sentiam, nulla diuersorum regnorum ratione habita. In hoc autem opusculo nullus erit fictioni locus, eam si excipias, quae ad lacum Mexicanum canentes Poetas inducit. Quae uidi refero, quaeque mihi testes oculati, caeteroquin ueracissimi, retulere. Praeterea curae mihi fuit oculatorum testium auctoritate subscripta, quae rariora sunt, confirmare. Ad fodinas quod attinet, plura in hoc carmine desiderari fateor. Neque enim mihi proposui exactissimam eius laboris notitiam exhibere; quippe qui magnae molis uolumen exigeret; sed praecipua dumtaxat, scituque digniora. Denique ut inoffenso pede carmen hocce percurras, Lector beneuole, te monitum uelim more me poetico locuturum, quotiescumque inanium Antiquitatis numinum mentio inciderit. Sancte equidem scio, ac religiose profiteor, huiusmodi commentitiis numinibus sensum nullum inesse, nedum uim, ac potestatem. Vereor tamen, ne dum ista percurreris, aliqua interdum suboscura offendas. In argumento quippe adeo difficili omnia latino uersu ita exprimere, ut uel rerum ignaris sub aspectum cadant, arduum quidem est; ne dicam impossibile. Nihilominus claritati, qua potui diligentia, ut prouiderem, plurimum in iis, quae nunc primum in luce prodeunt, adlaboraui: uulgata uero ad incudem reuocaui; in quibus plura mutaui, non nulla addidi, aliqua substraxi. Sed uerendum est adhuc, ne incassum desudauerim, neque eorum satis desiderio fecerim, qui in rebus etiam suapte natura difficillimis nullum uellent laborem impendere. Solacio tamen mihi erit, quod hac super re Golmarius Marsiglianus cecinit:

Heu! quam difficile est uoces reperire, modosque addere, cum nouitas integra rebus inest.

Saepe mihi deerunt (iam nunc praesentio) uoces: saepe repugnabit uocibus ipse modus. ${ }^{29}$

${ }^{28}$ El Monitum a la segunda edición (1782) figura después de la oda Vrbi Guatimalae, como una pausa que pone freno al fluir de las emociones del vate.

${ }^{29}$ Landívar R. M., Monitum: "Titulé este poema Por los campos de México, por un lado, porque casi todo lo que contiene atañe a los campos mexicanos; por otro, también porque oigo que en Europa se conoce vulgarmente toda la Nueva España con el nombre de México, sin tomar en cuenta la diversidad de territorios. En este opúsculo no tendrá 
Landívar echa luz fundamentalmente sobre tres virtudes: la claridad, la precisión y la diferencia. Así se refiere a distintos aspectos vinculados con la composición de su poema (título, carácter documental de su obra, fuentes, información minera limitada, función de las divinidades grecorromanas), alude a la índole realista de su obra y rechaza la ficción y la dimensión fantástica o simbólica. El poeta se atribuye el mérito de la veracidad y asegura haberse basado sobre la observación directa y el relato de testigos muy confiables, cuyas afirmaciones son refrendadas por voces autorizadas que dan fundamento y credibilidad al texto..$^{30}$

Con respecto a los libros VII y VIII, consagrados a los recursos mineros, el objetivo de Landívar no es ser minucioso, sino más bien evitar el detallismo y dejar a salvo su responsabilidad frente a los datos que no consignará. ${ }^{31}$ Es de notar que si bien la mayoría de los poemas didácti-

cabida la ficción, a excepción de la que introduce a los poetas cantando a la orilla del lago mexicano. Narro las cosas que vi y las que me refirieron testigos oculares, por otra parte muy veraces. Además me preocupé por comprobar las afirmaciones - pocas en verdad - sostenidas por la autoridad de los testigos. Confieso que en lo relativo a las minas falta mucho en este poema; pues no me propuse dar minuciosa información sobre esta actividad, dado que exigiría un libro voluminoso, sino principalmente acerca de lo fundamental y más digno de ser conocido. Finalmente, para que sin tropiezos recorras este poema, lector benévolo, quisiera advertirte que hablaré según el estilo poético, cuantas veces ocurriere nombrar las vanas divinidades de la Antigüedad. Pues sé honestamente y lo confieso con escrúpulo que tales númenes fabulosos no tienen facultad alguna, ni mucho menos fuerza y poder. Temo, sin embargo, que mientras leas esto encuentres algunos pasajes oscuros; pues expresar todo en verso acerca de tan difícil argumento, de modo que lo perciban aun los profanos, es por cierto ardua tarea, por no decir imposible. Con todo, para atender a la claridad con la mayor diligencia posible, trabajé empeñosamente en esto que ahora por primera vez sale a la luz pública, en verdad convoqué al yunque lo ya divulgado, introduje varios cambios, añadí algunas cosas y suprimí otras. Pero debo temer además haber sudado en vano, sin haber satisfecho el deseo de los que, aun en asuntos dificilísimos por su propia naturaleza, no quieren gastar ningún esfuerzo. Sin embargo, sírvame de consuelo lo que sobre todo esto cantó Golmario Marsigliano: 'Oh cuán difícil es hallar vocablos y descubrir metros, en asuntos totalmente nuevos. Con frecuencia (ya desde ahora lo presiento), me faltarán las palabras y a menudo el ritmo se rebelará contra las voces"”.

${ }^{30} \mathrm{La}$ indicación de fuentes y autoridades de apoyo o la mención de documentos complementarios se despliegan en las notas al pie, consideradas elementos del paratexto. Sobre la arquitectura peritextual de la Rusticatio, cf. Suárez 2007 y 2009.

${ }^{31}$ Ambos cantos representan un himno al trabajo y al hombre, tenaz en la lucha con la naturaleza y hábil para obtener sus beneficios. En opinión de Rodríguez Gil (1952, p. 50), dichos libros son los más áridos de leer porque en ellos predomina la parte didáctica. Sin embargo, el didactismo es uno de los aspectos más destacados del carmen landivariano. 
cos fueron escritos por maestros, "Jesuit didactic poets were not usually professional teachers of subjects of their poems", en palabras de Haskell (2003, p. 5).

Movido por escrúpulos de orden teológico y en prevención de la censura, el jesuita advierte al lector que ha de mencionar reiteradas veces a las divinidades antiguas. La presencia de éstas responde a una exigencia de la tradición, entendida, en términos de Conte (1986, p. 37), como una precondición necesaria para la aemulatio y la alusión, aunque, tal como lo observa Laird (2006, p. 52), posiblemente Landívar haya querido marcar la diferencia entre su propia práctica poética y el estilo más literal de su antecesor, el jesuita Jacques Vanière, quien hizo explícita su decisión de emplear temas del mito clásico.

Pero, lo que es más importante, Landívar presupone un tipo de lector, valorado mesuradamente (Lector beneuole), ${ }^{32}$ como destinatario real de su obra: el europeo culto de la Ilustración, desconocedor de América. Transmitir información acerca de lo americano responde, pues, a una clara finalidad didáctica que se suma a la intención de propiciar otro tipo de relaciones internacionales con los europeos, diferentes de las existentes entonces con América.

La poesía didáctica no sólo exige herramientas técnicas, sino además una mentalidad literaria predispuesta a la disciplina y a la diligentia para luego emprender la tarea de ordenar el material y escribir. En este sentido, hay que destacar la pertinencia del modificado verbal adlaborare, definido como addere cum labore, ${ }^{33}$ a propósito de la tarea de reescritura y transformación que el autor jesuita ${ }^{34}$ decidió llevar a cabo entre la editio princeps (1781) y la editio altera (1782). ${ }^{35}$

32 Según la tradición literaria, el autor acostumbra alabar o vituperar en el prólogo a los lectores. En opinión de Marrero Fente (1999, p. 86), las llamadas de afecto positivo se mueven desde el elogio desmedido hasta la más cruel indiferencia, crueldad o insulto.

${ }^{33}$ Cf. ThLL, s. v.

${ }^{34}$ La imagen del yunque (incus) y la caracterización del proceso de creación reflejan precisamente el método de composición recomendado por Horacio ( $P$. 438-441), quien ataca el ornamento ambicioso y la frase ambigua. Landívar declara, pues, la filiación de sus principios poéticos con los que el poeta latino plantea en el Ars. Cf. Laird 2006, p. 53.

${ }^{35}$ En la segunda edición de la Rusticatio (Bolonia 1782), Landívar retoma el discurso del Monitum de 1781 y agrega un quinto parágrafo donde incorpora elementos en respuesta a posibles reacciones del público y la crítica. 
Landívar busca retener al lector con un aparato retórico que apunta a la captatio beneuolentiae, y se esfuerza por lograr dicha captatio apelando al tópico de la modestia, valorizando el tema e insistiendo, a partir de su autoconciencia poética, en la imposibilidad de expresar en hexámetros latinos temas nuevos y desconocidos para el europeo: lo maravilloso americano. ${ }^{36}$ Así, pues, legitima su insuficiencia lingüística activando su memoria poética ${ }^{37}$ y recordando al jesuita y humanista italiano Golmario Marsigliano, seudónimo de Hyeronimus Lagomarsini, ${ }^{38}$ quien en sus dísticos elegíacos destaca la dificultad de cantar en latín temas de difícil descripción. En su doble rol de magister y poeta, Landívar retoma de este modo el tópico de la egestas linguae latinae, que ha marcado a la antigua poesía didáctica. ${ }^{39}$

Múltiples son los modelos literarios del género didáctico que han dejado su huella en la Rusticatio Mexicana, ${ }^{40}$ pero sin duda Virgilio representa el referente supremo. Landívar imita al mantuano a partir de una transformación compleja e indirecta que exige la constitución previa de un modelo de competencia genérica, surgido básicamente de las Geórgicas. ${ }^{41}$ Baste como ejemplo el Libro VI, cuyo hipotexto es el Libro IV de las Geórgicas. Así como Virgilio elige la sociedad de las abejas, una utopía cuasiplatónica en la que el trabajo es el valor social supremo, no sólo por la descripción pintoresca y antropomórfica que puede lograr, sino además por las vinculaciones sociales y morales que la especie le ofrece,

${ }^{36}$ En opinión de Vargas Alquicira (1986, p. 49), "lo maravilloso americano" es un fenómeno literario que abarca tres temas fundamentales: la antigua cultura indígena, la ciudad de México y sus riquezas y la Virgen de Guadalupe. Por su parte, Heredia Correa (1994) se refiere a cuatro temas de la cultura novohispana que tienen una importancia primordial en la conformación de una conciencia de identidad nacional: la geografía y el territorio, la oposición criollos-peninsulares, la comunidad de costumbres, instituciones y tradiciones, y la asunción por parte de los criollos de la historia de los pueblos indígenas como su propia historia.

37 Tomamos aquí la expresión de Conte 1986.

38 Golmarius Marsiglianus o Hyeronimus Lagomarsini (1698-1773) se desempeñó como profesor de Retórica en Florencia desde 1732, donde abordó el estudio de autores clásicos latinos y, muy especialmente, la obra de Cicerón.

${ }^{39}$ Cf. Lucr. I.136-139; Manil. 3.31-34.

${ }^{40}$ Muchos otros autores de la Antigüedad clásica y el Renacimiento han dejado su huella en el poema landivariano: Homero, Hesíodo, Lucrecio, Horacio, Ovidio, Lucano, Plinio, Apuleyo, Petrarca, Fracastoro y Tomás Moro.

${ }^{41}$ Acerca de la hipertextualidad de la Rusticatio Mexicana, cf. Suárez 2006. 
el jesuita opta por los castores. En efecto, a partir del valor comunitario encarnado en la sociedad de estos mamíferos, es posible reconstruir una lectura metafórica, casi inexistente en el resto de los cantos, y lograr la síntesis entre la valoración típica del homo naturalis propia de su época y las ideas sobre la convivencia social que maneja la tradición jesuítica. A partir de esta lectura, se comprueba la finalidad didáctica de la obra $\mathrm{y}$, en consecuencia, el proyecto ideológico del autor. Asimismo, en virtud de la configuración del castor como agente de una estructura social altamente racionalizada, el poeta reconsidera la imagen de América y, si bien no discute abiertamente la condición colonial de su patria, se vale de la utopía para exaltar, por un lado, los beneficios de la libertad y del gobierno autónomo y, por otro, la representación del espacio americano no como un ámbito indomable, sino como una eutopía, es decir, el lugar del cumplimiento de las antiguas profecías, el buen lugar concebido como el producto de una dialéctica entre naturaleza y artificio. ${ }^{42}$

Landívar utiliza el texto virgiliano como modelo genérico y como modelo ejemplar. ${ }^{43}$ Ahora bien, la supremacía de Virgilio y la utilización de Geórgicas como hipotexto responde no sólo al principio de la imitatio et aemulatio ueterum enarbolado por la Ratio Studiorum, sino también a una corriente ideológica más profunda. ${ }^{44}$

El paradigma pedagógico ignaciano ${ }^{45}$ aporta la visión de un proceso didáctico dividido en cinco etapas (contextualización, experiencia, reflexión, acción y evaluación), en el que se combinan trabajo/esfuerzo y aprendizaje, acción y contemplación. ${ }^{46}$ Por tal razón, según Haskell (2003, p. 15), la imitatio de las Geórgicas comienza entonces cuando los jesuitas descubren en esta obra "the ideal venue for figuring and affirming the ignatian wedding of action and contemplation".

${ }^{42}$ Cf. Suárez 2005.

${ }^{43}$ Este planteamiento es el que permite abordar un camino intermedio entre la ausencia y la omnipresencia del autor. Toda semejanza textual no se explica sólo como el resultado de la intencionalidad de un sujeto literario, sino también como un modo de funcionamiento del texto que surge de una codificación literaria común que prevé la asimilación y transformación de lenguajes diversos. Cf. Conte 1986, p. 28.

${ }^{44}$ Cf. Haskell 2003, p. 15.

${ }^{45}$ El paradigma pedagógico ignaciano emerge de la experiencia de Ignacio de Loyola, de sus cartas, de sus Constituciones (1540) y de sus reglas (Ratio Studiorum 1599).

${ }^{46}$ Ambas instancias son consideradas como facetas del esfuerzo religioso individual. Cf. Harris 1989, p. 51. 
El trabajo (labor) es uno de los elementos ideológicos fundamentales en la producción literaria de los jesuitas, y el poema landivariano no es una excepción. En la Rusticatio es entendido como actividad física y como actividad intelectual. El labor individual es elogiado reiteradas veces, pero el labor socius, ${ }^{47}$ es decir, el trabajo en común, que implica una suerte de ayuda comunitaria, ocupa un lugar preponderante. Landívar da cuenta de las notables capacidades indígenas y enfatiza el valor moral del esfuerzo conjunto al servicio del bien común y del amor patrio.

Con respecto al labor entendido como actividad intelectual, en la Appendix encontramos la ocurrencia más importante, ${ }^{48}$ justamente por su vinculación con el aprendizaje:

En tibi, primaeuo florens ardore iuuentus, cui caelo natura dedit gaudere benigno, atque aures mulcere auibus, pictisque tueri libratas pennis caeli per inania turbas, cuique herbosus ager late uiridantia praebet gramina, odorifero semper fulgentia flore; en tibi, queis taetras, uiolenti ad littora Reni, fallere conabar curas, atque otia, cantus. Disce tuas magni felices pendere terras, diuitiasque agri, praestantia munera caeli, explorare animo, ac longum indagare tuendo. Alter inauratos Phoebeo lumine campos incautis oculis, brutorum more, sequatur, omniaque ignauus consumat tempora ludis.

Tu tamen interea, magnum cui mentis acumen, antiquos exuta, nouos nunc indue sensus, et referare sagax naturae arcana professa ingenii totas uestigans exere uires, thesaurosque tuos grato reclude labore. ${ }^{49}$

${ }^{47}$ Cf. OLD, s. v. (3) y (4).

${ }^{48}$ En $R . M$. V.10-11, el poeta pide asistencia a Minerva para que dirija su labor poética, referida en este caso a la industria del añil: Ne tamen ipse tuos euertam nescius agros / Dextra faue, praesensque meum moderare laborem ("Para que yo mismo, sin saber, no destruya tus campos, ayúdame y siéndome favorable dirige mi labor"). Las otras ocurrencias del lexema apuntan a la actividad intelectual.

${ }^{49}$ Landívar, R. M., App. 94-112: "He aquí para ti, juventud que floreces con el ardor de la primera edad, a quien la naturaleza concedió gozar un clima benigno, endulzar los 
Dalzell (1996, p. 33) ${ }^{50}$ considera que lo que separa a un autor de otro en la clasificación de la poesía didáctica es la actitud que el poeta adopta frente al lector y a su mensaje didáctico.

Conviene recordar que el espíritu cientificista del siglo XVIII es contradictorio con respecto al continente joven. Algunas de las teorías circulantes tienen como objetivo disminuir el valor y la importancia de un baluarte de España, foco de interés económico para el resto de Europa. ${ }^{51}$ Es durante la vigencia de estas ideas cuando, tras la expulsión, los jesuitas novohispanos arriban al viejo mundo. Poco se sabe allí de América. ${ }^{52}$ Poco y mal..$^{53}$ Landívar focaliza entonces su atención en el enunciatario

oídos con el canto de las aves y contemplar sus bandadas disparándose a través del cielo con sus alas multicolores y a quien el campo cubierto de hierbas ofrece generosamente gramíneas verdegueantes, que deslumbran con flores perfumadas; he aquí para ti, los cantos con los cuales intentaba engañar mis luctuosas preocupaciones y mi ocio a orillas del impetuoso Reno. Aprende a valorar tus fértiles tierras, a explorar animosamente y a investigar contemplando ampliamente las riquezas del campo, los excelentes dones del cielo. Sea otro el que siga las campiñas doradas por la luz del sol, con los ojos incautos, como los animales, y dilapide indolente todo el tiempo en juegos. Pero, tú, que posees gran agudeza de entendimiento, despójate de las antiguas ideas y vístete ahora con las nuevas y resuelta a develar sagazmente los misterios de la naturaleza, ejercita en la búsqueda todas las energías de tu inteligencia y con gustoso esfuerzo descubre tus riquezas".

${ }^{50}$ Dalzell (1996) rompe con la noción de género como una taxonomía estática compuesta por un conjunto de normas, y considera al género como una estrategia de lectura que permite iluminar nuevos sentidos en los textos. En su obra presenta el análisis de tres poemas didácticos (De Rerum Natura, Georgicon, Ars amatoria), no como tres tipos de poesía didáctica, sino como ejemplos de obras que difieren entre sí, precisamente, por la actitud que el autor asume frente al lector y al mensaje didáctico.

${ }^{51}$ Un científico tan prestigioso como George Buffon, en su Historia natural universal (1749), pone en tela de juicio varios de los beneficios atribuidos a la naturaleza americana. Aún más vehemente es el prusiano Cornelius de Pauw, que, en su obra $R e$ cherches Philosophiques sur les Americains (1772), habla, sin pruebas científicas, de la naturaleza embrutecida de los criollos, indígenas y mestizos.

52 Al respecto, dice Browning (1985, p. 14): "It is reasonable to suppose, therefore, that Landívar wrote for the same reasons that Clavijero, Molina, Jolís and others wrote: to combat the widespread belief that America was an unhealthy continent, peopled by squalid savages and stupid creoles, and to present a detailed, accurate, scientific picture of the New World which would enlighten Europeans and Americans alike".

${ }^{53}$ La situación de desterrados les permite, entonces, refutar teorías y producir obras literarias que son la máxima expresión del fenómeno denominado "singularidad novohispana". Dicha expresión le pertenece a Paz (1977, p. 15), quien dice: "La conciencia de la singularidad novohispana aparece temprano, al otro día de la conquista [...]". 
real, el europeo, y, a través de su poema, se propone enseñarle (docebo $)^{54}$ las excelencias americanas (los lagos mexicanos, las cataratas guatemaltecas, la fauna autóctona, la ganadería, los rubros económicos, los juegos, entre otras).

Sin embargo, el poeta dedica su carmen a un destinatario anónimo, cuya identidad descubre hacia el final de su obra, en el apéndice: la juventud novohispana (primaeuo florens ardore iuиеntus, App. 94). En el verso 102 , el poeta vuelve a apelar a una de las convenciones genéricas - la autoridad - y se vale del imperativo (disce) para exhortarla a una triple acción (pendere, explorare, indagare) que requiere la contemplación (tuendo) del propio entorno. Nótese el empleo de la recusatio, que le permite a Landívar establecer una oposición entre la iuuentus y un alter asociado a la inacción (ignauus), al descuido (oculis incautis) y al desinterés por el conocimiento (brutorum more), según se desprende de los versos 105-107: Alter inauratos Phoebeo lumine campos / incautis oculis, brutorum more, sequatur, / omniaque ignauus consumat tempora ludis. ${ }^{55}$

Finalmente, la iuuentus es incitada a renovarse (nouos induere sensus), a ejercitar sus energías (exere uires) y a descubrir sus riquezas (thesauros recludere). Pero nada de esto es posible sin la intervención del labor, es decir, sin trabajo y sin esfuerzo.

Este proceso didáctico en el que se combinan aprendizaje y labor alude en cierto modo a alguna de las etapas que caracterizan el paradigma pedagógico jesuita, es decir, la contextualización que implica tener en cuenta la realidad que nos rodea, la experiencia que supone confrontar los saberes conocidos con los nuevos, la reflexión que apunta a descubrir el valor de la formación y el estudio.

La exhortación a la juventud implica, pues, una suerte de identificación entre formación, saber, virtud y estudio, lo cual se relaciona estrechamente con el sentido de servicio que los jesuitas le otorgaron a la enseñanza dentro de un discurso marcadamente humanista. Los versos finales expresan, sin dudas, el afán didáctico, declaran explícitamente un pensamiento que invita a participar en actividades intelectuales y promueven la innovación, la investigación y el trabajo: un corpus ideo-

\footnotetext{
${ }^{54}$ Conviene recordar que Virgilio utiliza el lexema docebo en G. III.440: Morborum quoque te causas et signa docebo.

55 "Sea otro el que siga las campiñas doradas por la luz del sol, con los ojos incautos, como los animales, y dilapide indolente todo el tiempo en juegos."
} 
lógico marcado por la impronta de la Compañía de Jesús, revelador de un Landívar maduro, que proclama un mensaje orientado hacia la acción que es transformación y hacia el compromiso con la realidad americana, esto es, un mensaje claramente identitario.

\section{Conclusión}

En palabras de Haskell (2003, p. 2), "early modern didactic poems by Jesuits reveal much, not only about early modern Jesuits, but about local literary fashions and the classical tradition, about social mores, contemporary events and inventions, and about circulation of scientific and cultural knowledge". De esto se trata el didactismo, en última instancia, de la actitud que el escritor asume frente a su mensaje y a su lector.

Landívar es un poeta esencialmente didáctico, cuyo carmen - según hemos señalado - toma préstamos de la tradición clásica y se apropia fundamentalmente del texto virgiliano como modelo genérico y como modelo ejemplar o específico, para interrogarlo sobre las posibilidades que ofrece la creación de motivos y temas, pero no con la intención de copiarlos mecánicamente, sino para integrarlos y darles una nueva significación.

La actitud del jesuita respecto de los enunciatarios (el europeo y la iuuentus novohispana) y del mensaje didáctico se traduce en conocimiento y valorización de lo propio, aspectos ambos que se convierten en rasgos esenciales y originales de su obra. A esto se suma, también, el hecho de que el poema hace gala del ideario pedagógico de la Compañía.

En síntesis, el análisis de ciertos pasajes y de algunas marcas genéricas esenciales pone de manifiesto que el didactismo landivariano se nutre de la tradición clásica y la imitación creativa, y revela un carácter identitario y claramente ideológico, fundado en los ideales y prácticas de la Ratio Studiorum, en el ethos del esfuerzo y la emulación, y en una actitud comprometida y transformadora en defensa de la identidad cultural. 


\section{BIBLIOGRAFÍA}

\section{Fuentes}

LANDIVAR, Raphaelis, Rusticatio mexicana. Editio altera auctior, et emendatior Bononiae, ex Typographia S. Thomae Aquinatis, 1782.

[LANDÍvar Rafael,] Rusticatio Mexicana, seu rariora quaedam ex agris mexicanis decerpta, atque in libros decem distributa a Raphaele Landivar, Mutinae apud Societatem Typographicam, 1781.

\section{Estudios}

Browning, J., "Rafael Landívar's Rusticatio Mexicana and the Political Subversion", Ideologies and Literature, 1, 3, 1985, pp. 9-30.

Burrieza SÁnchEZ, J., "La estrategia y antiguo ministerio educativo en la antigua Compañía de Jesús (siglos XVI-XVIII)", en J. Beltrán (dir.), La compañía de Jesús y su proyección mediática en el mundo hispánico durante la Edad Moderna, Madrid, Silex, 2010, pp. 179-218.

Conte, G. B., The Rhetoric of Imitation, Ithaca, New York, Cornell University Press, 1986.

Dalzell, A., The Criticism of Didactic Poetry: Essays on Lucretius, Virgil and Ovid, Toronto, University of Toronto Press, 1996.

Gibson, R., "Didactic Poetry as 'Popular' Form: a Study on Imperatival Expressions in Latin Didactic Verse and Prose", en C. Atherton (ed.), Form and Content in Didactic Poetry, Bari, Levante, 1997, pp. 67-115.

GIL, E., El sistema educativo de la Compañía de Jesús. La Ratio Studiorum, Estudio histórico y pedagógico. Bibliografía, Madrid, Pontificia Universidad de Comillas, 1992.

Habinek, T., The Politics of Latin Literature, Princeton, Princeton University Press, 1998.

HARrIS, S., "Transposing the Merton Thesis: Apostolic Spirituality and the Establishment of the Jesuit Scientific Tradition", Science in Context, 3, 1989, pp. 29-65.

Haskell, Y., Loyola's Bees. Ideology and Industry in Jesuit Latin Didactic Poetry, Oxford, Oxford University Press, 2003.

_, \& Ph. H. Hardie (eds.), Poets and Teachers: Latin Didactic Poetry and the Didactic Authority of the Latin Poet from the Renaissance to the Present, Bari, Levante, 1999.

Heredia Correa, R., "El neolatín en los orígenes de nuestra identidad nacional”, Noua Tellus, 12, 1994, pp. 197- 213.

Higgins, A., Constructing the Criollo Archive. Subjects of Knowledge in the Bibliotheca Mexicana and the Rusticatio Mexicana, Indiana, Purdue University Press, 2000. 
IJSEwijn, J., Companion to Neo-Latin Studies, Amsterdam, North Holland Pub. Co., 1977.

__, \& D. SaCré, Companion to Neo-Latin Studies (Part II), Amsterdam, Leuven University Press, 1998.

Kromer, G., "The Didactic Tradition in Vergil's Georgics”, Ramus, 8, 1979, pp. 7-21.

LAIRD, A., The Epic of America. An Introduction to Rafael Landivar and the Rusticatio Mexicana, London, Duckworth, 2006.

MARrero Fente, R., Al margen de la tradición. Relaciones entre la literatura colonial y peninsular en los siglos XV, XVI y XVII, Madrid, Fundamentos, 1999.

Nemes, G., "Rafael Landivar and Poetic Echoes of the Enlightenment", en A. Owen Aldrige (ed.), The Iberoamerican Enlightenment, Urbana, University of Illinois Press, 1971.

PAZ, O., "Prefacio", en J. Lafaye, Quetzacóalt y Guadalupe. La formación de la conciencia nacional en México, México, Fondo de Cultura Económica, 1977.

Ratio atque Institutio Studiorum Societatis Iesu [1586 1591 1599], Noua editio penitus retractata, edidit Ladislaus Lukács S. I., Monumenta Paedagogica Societatis Iesu, V, Romae, 1986.

Pozzi, M., "Aproximaciones a la poesía didáctica latina”, en A. Schniebs (coord.), Debates en lenguas clásicas, Buenos Aires, Editorial de la Facultad de Filosofía y Letras, Universidad de Buenos Aires, 2010, pp. 105-130.

RodríGuez GIL, S., La originalidad de Landívar, México, Universidad Nacional Autónoma de México, 1952.

SuÁrez, M., "La utopía de los castores o la representación del espacio americano en el L.VI de la Rusticatio Mexicana”, en $2^{\circ}$ Encuentro Las Metáforas del viaje y sus imágenes. La Literatura de viajeros como problema, Rosario, Universidad Nacional de Rosario, 2005.

__, Landivar y Virgilio. La hipertextualidad de la Rusticatio Mexicana. Tesis doctoral, Buenos Aires, Facultad de Filosofía y Letras, Universidad de Buenos Aires, 2006.

__, "Acerca de la génesis de la Rusticatio Mexicana: la arquitectura peritextual", Incipit, 27, 2007, pp. 231-247.

__, "Oculatorum testium auctoritate subscripta confirmare: la práctica de las notas en la Rusticatio Mexicana”, Bibliographica Americana, 5, 2009 (revista virtual).

VAn ThIEgEm, P., La Littérature Latine de la Renaissance. Étude d'histoire littéraire européenne, Genève, Albin Michel, 1966.

VARgas Alquicira, S., La singularidad novohispana en los Jesuitas del s. XVIII, México, Universidad Nacional Autónoma de México, 1986.

Volk, K., The Poetics of Latin Didactic. Lucretius, Vergil, Ovid, Manilius, Oxford, Oxford University Press, 2002. 